\title{
Unas palabras introductorias al artículo de Roberto Lobato Corrêa
}

\author{
4 María Laura Silveira \\ CONICET - Universidad de Buenos Aires. Facultad de Filosofía y Letras. Instituto de \\ Geografía "Romualdo Ardissone". Buenos Aires, Argentina.
}

En este número de Punto Sur inauguramos una sesión de Teoría y Método con el propósito de retomar debates importantes de nuestra disciplina, así como también dar lugar a nuevas discusiones. Iniciamos nuestro recorrido compartiendo con los lectores el artículo “Tiempo, Espacio y Geografía - Un Ensayo", de autoría de Roberto Lobato Corrêa.

De reciente elaboración, este texto puede ser visto como una exposición profunda y sintética de su pensamiento y como uno de sus aportes más importantes. Sin embargo, como en todo intelectual de gran trayectoria, su contribución debe buscarse en el conjunto variado de su obra y no únicamente en una de sus piezas.

Aunque fue publicado originalmente en lengua portuguesa, ${ }^{1}$ consideramos relevante traducir este artículo al español con el propósito de aumentar su difusión, inclusive más allá del ambiente académico y, al mismo tiempo, propiciar un debate sin distorsiones idiomáticas y una correcta operacionalización de las categorías propuestas. Añádase a esos objetivos el reconocimiento del hecho de que no son muchas las obras del autor publicadas en español. Lamentablemente, nunca fueron traducidos dos libros ya clásicos como $O$ espaço urbano y A rede urbana, a pesar de su significativa circulación no sólo entre profesores e investigadores, sino también entre estudiantes en nuestras universidades.

Habiendo trabajado entre 1959 y 1993 en el Departamento de Geografia del Instituto Brasileiro de Geografia e Estatística-IBGE y, desde 1971, en el Departamento de Geografia de la Universidade Federal do Rio de Janeiro, el Dr. Lobato Corrêa ha tenido una permanente y activa presencia en la Associação dos Geógrafos Brasileiros-AGB. Geógrafo, profesor e investigador en diferentes ámbitos nacionales e internacionales, su producción científica revela una preocupación con la historia, la crítica, la definición y la operacionalización de las categorías centrales de la disciplina, convocando a un debate abierto y constructivo. Sus lectores asiduos ya esperan, al final de cada texto y como es característico, una propuesta de nuevos temas y fuentes ofrecidos a la comunidad geográfica como verdaderas pistas de investigaciones necesarias. 
Es así que, si analizamos el conjunto de su producción, encontraremos elaboraciones rigurosas sobre conceptos y nociones de espacio, tiempo y periodización, espacio urbano, región, paisaje, red geográfica, red urbana, metrópolis, ciudad media, ciudad pequeña, escala, procesos espaciales, formación espacial, área social, organización espacial de las empresas y centros de gestión territorial que han marcado significativamente la elaboración de tesis e investigaciones en la geografía brasileña. A ese camino de investigación en geografía urbana y epistemología se le agregó, hace poco más de dos décadas, una vasta obra sobre Geografía Cultural, en gran parte llevada a cabo con Zeny Rosendahl.

En el artículo que aquí presentamos, nos encontramos con un difícil ejercicio de reconocer y transformar categorías universales -oriundas de la filosofía y por ello utilizables en las disciplinas particulares- tales como tiempo, espacio, movimiento, pausa, proceso y forma en un corpus sustantivo de la geografía que permita eficazmente aprehender lo real. En tanto manifestaciones de una unidad, los pares de categorías filosóficas seleccionados dan lugar a categorías geográficas. Temporalidad y espacialidad constituyen la armonía que enlaza los acordes de conceptos como refuncionalización e interacciones espaciales, por mencionar sólo algunos. Este esfuerzo, que no deja de lado la génesis y las posibilidades de utilización de cada categoría, es de alguna manera una interpelación a los modos de pensar ya consolidados. Una lectura despejada de este ensayo podrá contribuir a pensar y repensar nuestros esquemas de interpretación de lo real. Éste también es un ejercicio siempre necesario, aún más en un mundo que se transforma tan aceleradamente y en el cual los saberes particulares necesitan renovar sus coherencias.

Podríamos finalizar esta breve introducción con algunas de las palabras que Milton Santos escribió en el prefacio de uno de los libros de este autor: "Quien acompaña su obra, que ocupa honrosamente el panorama geográfico brasileño de los últimos 40 años, sabe de su fidelidad a la disciplina de la cual hizo un verdadero combate. Allí donde es necesario mostrar el papel de la geografía y del espacio, allí Roberto Lobato Corrêa está presente" (Corrêa, 1997:9). ${ }^{2}$ 